\title{
Penatalaksanaan Fisioterapi Komprehensif Pada Kasus Pasca Coronary Artery By Pass Grafting Et Causa Coronary Artery Disease Involving 3 Vessels (CAD3VD): Case Report
}

\author{
${ }^{1}$ Nurisma Pramudiana, ${ }^{2}$ Arif Pristianto \\ Program Studi Profesi Fisioterapis, Fakultas Ilmu Kesehatan, Universitas Muhammadiyah Surakarta \\ Jl. A.Yani Tromol pos I Pabelan Kartasura Telp.(0271) 717417 Fax. (0271) 715448 Surakarta 57162 \\ Email : nurismap22@gmail.com
}

\begin{abstract}
ABSTRAK
Penyakit jantung koroner adalah gangguan fungsi jantung disebabkan karena adanya stenosis pembuluh darah jantung yang dapat mempengaruhi satu atau lebih arteri. Pada kasus ini pasien mengalami Triple Vessels Disease (3-VD), dimana terdapat stenosis $\geq 50-70 \%$ pada sebagian besar cabang utama dari pembuluh darah jantung, kemudian pasien melakukan operasi revaskularisasi Coronary Artery Bypass Grafting (CABG) dengan kondisi pasca operasi yaitu nyeri pada area sternum dan tungkai kanan bawah, penumpukan sputum paru, penurunan ekspansi thoraks, sesak nafas, penurunan kemampuan aktifitas dan fungsional. Penatalaksanaan fisioterapi yang diberikan yaitu Chest physiotherapy dan latihan aktif serta pasif pada ektremitas. Setelah dilakukan terapi sebanyak 3 kali, diperoleh hasil derajat sesak T0: 5 menjadi T3: 3, penurunan nyeri gerak T0: 6 menjadi T3: 3, kemudian nyeri tekan T0: 6 menjadi T3: 3 dan nyeri diam T0: 4 menjadi T3: 3, peningkatan selisih ekspansi thorak pada axilla T0: $1 \mathrm{~cm}$ menjadi T3: $2 \mathrm{~cm}$, pada ICS T0:1 $\mathrm{cm}$ berubah menjadi T3: $2 \mathrm{~cm}$ dan belum ada peningkatan di processus xypoideus, sebesar $2 \mathrm{~cm}$ pada T0 dan T3. Kemampuan aktifitas dan fungsional di hitung menggunakan index barthel pada T0 kategori ketergantungan total, berubah menjadi T3: ketergantungan berat. Chest physiotherapy dan latihan aktif-pasif ekstremitas dapat mengatasi problematika pasca operasi $C A B G$.
\end{abstract}

Kata kunci: Coronary Artery By Pass Grafting, Chest Physiotherapy, latihan aktif dan pasif pada ekstremitas

\section{ABSTRACT}

Coronary heart disease is a malfunctioning of the heart caused by stenosis of the heart blood vessels which can affect one or more arteries. In these cases the patient had Triple Vessels Disease (3-VD), where there was $\geq 50-70 \%$ stenosis in most of the main branches of the heart blood vessels, then the patient underwent a revascularization operation Coronary Artery Bypass Grafting (CABG) with a postoperative condition, namely pain. in the sternum and lower right leg, accumulation of pulmonary sputum, decreased thoracic expansion, shortness of breath, decreased activity and functional ability. The management of physiotherapy that is given is chest physiotherapy and active and passive exercises in extremity. After 3 times of therapy, the results obtained from the degree of shortness of T0: 5 to T3: 3, the decrease in pain T0: 6 to T3: 3, then tenderness T0: 6 to T3: 3 and silent pain T0: 4 to T3: 3 increased the difference in thoracic expansion in the axilla T0: $1 \mathrm{~cm}$ becomes T3: $2 \mathrm{~cm}$, at ICS TO: $1 \mathrm{~cm}$ changes to T3: $2 \mathrm{~cm}$ and there has been no increase in the xypoideus process, by $2 \mathrm{~cm}$ at TO and T3. Activity and functional abilities were calculated using the Barthel index on T0 of the total dependency category, changing to T3: weight dependence. Chest physiotherapy and active-passive exercises in extremity can alleviate problems in post$C A B G$ surgery.

Keywords: Coronary Artery Bypass Grafting, Chest Physiotherapy, active and pasive exercise in extremity

ISSN 2722-9610

E - ISSN 2722-9629 


\section{PENDAHULUAN}

Jantung merupakan salah satu organ terpenting dalam kehidupan manusia, namun pada beberapa kondisi dapat mengalami gangguan misalnya penyakit jantung koroner yang menjadi salah satu penyebab utama terjadinya kematian di dunia. Faktor resiko yang dapat menyebabkan penyakit jantung koroner diantaranya yaitu diabetes mellitus (DM), hipertensi, hiperkolesterolemia, merokok, penyakit ginjal kronis, usia, obesitas, kebiasaan sehari-hari dan dislipedemia (ArroyoRodríguez et al., 2018)

Menurut Seo et al., 2017 prevalensinya terus meningkat selama periode 30 tahun (19832012) kemudian berdasarkan data Riset Kesehatan Dasar tahun 2018, prevalensi penderita PJK di indonesia berdasarkan diagnosis dokter sebanyak $1,5 \%$ dengan peringkat prevalensi tertinggi adalah Provinsi Kalimantan Utara (2,2\%), Daerah Istimewa Yogyakarta (2\%) dan Provinsi Gorontalo (2\%). Kemudian terdapat beberapa provinsi yang melebihi prevalensi nasional diantaranya Provinsi DKI Jakarta (1,9\%) dan Provinsi Jawa Tengah (1,6\%) (Kementerian Kesehatan, 2019)

Penyakit jantung koroner adalah gangguan fungsi jantung disebabkan adanya stenosis pembuluh darah coroner karena pengendapan plak aterosklerotik, sehingga dapat mempengaruhi satu atau beberapa arteri (multi vessel). Pada kasus ini pasien mengalami Triple Vessels Disease (3-VD) dimana terdapat stenosis $\geq 50-70 \%$ pada sebagian besar cabang utama dari pembuluh darah jantung (Purnomowati et al., 2013). Sebagian besar pasien dengan kondisi ini direkomendasikan untuk melakukan tindakan revaskularisasi jantung, tindakan yang biasanya dilakukan yaitu operasi Coronary Artery By Pass Grafting (CABG) atau pemasangan cincin jantung, tergantung dengan kondisi pasien (Arroyo-Rodríguez et al., 2018)

Pasien ini melakukan operasi CABG yang mengalami kondisi pasca operasi diantaranya kesulitan untuk mengembangkan paru-parunya yang mengakibatkan volume paru-paru berkurang sehingga pertukaran gas terganggu dan menyebabkan komplikasi diantaranya dispnea (sesak nafas), tidak adanya reflek batuk, gagal nafas, pneumonia, atelektasis dan eksaserbasi penyakit paru-paru. Komplikasi terjadi disebabkan oleh trauma pasca bedah, anastesi umum, pembukaan thoraks, efusi pleura, hilangnya kemampuan bergerak thoraks dan fungsi diafragma, peningkatan cairan intestinal paru-paru (Westerdahl, 2015)

Hal-hal diatas menyebabkan problematika diataranya nyeri pasca operasi pada area sternum dan tungkai kanan bawah, penumpukan sputum, penurunan ekspansi thoraks, sesak nafas dan penurunan kemampuan aktifitas dan fungsional. Penatalaksanaan fisioterapi yang dapat diberikan yaitu chest physiotherapy (deep breathing exercise, chest wall percussion, latihan batuk efektif dan positioning) dan latihan aktif-pasif ekstremitas (Sultanpuram et al., 2016)

\section{METODE PENELITIAN}

Metode penelitian menggunakan studi case report yang dilaksanakan di Rumah Sakit Umum Pusat Dr. Kariadi, Semarang pada pasien Tn. Tusia 50 tahun dengan diagnosa medis pasca Coronary Artery Bypass Grafting (CABG) et causa Coronary Artery Disease Involving 3 Vessels Disease (CAD3VD). Pasien telah menjalani terapi sebanyak 3 kali dengan pemberian intervensi fisioterapi berupa Chest physiotherapy (deep breathing exercise, chest wall percussion, latihan batuk efektif dan positioning) dan latihan aktif-pasif ekstremitas.

Intervensi diatas digunakan untuk mengurangi nyeri pada area sternum dan tungkai kanan bawah, penumpukan sputum paru, penurunan ekspansi thorak, sesak nafas, penurunan kemampuan aktifitas dan fungsional. 
Pramudiana N. \& Pristianto A.

Fisiomu.2022 Vol 3(1): 8-15

DOI: $10.23917 /$ fisiomu.v3i1.12960

\section{HASIL}

\section{Evaluasi Derajat Nyeri dengan Numerical Rating Scale (NRS)}

Gambar 1. Hasil Evaluasi Derajat Nyeri pada area incisi pada Os.Sternum dan Tungkai kanan bawah

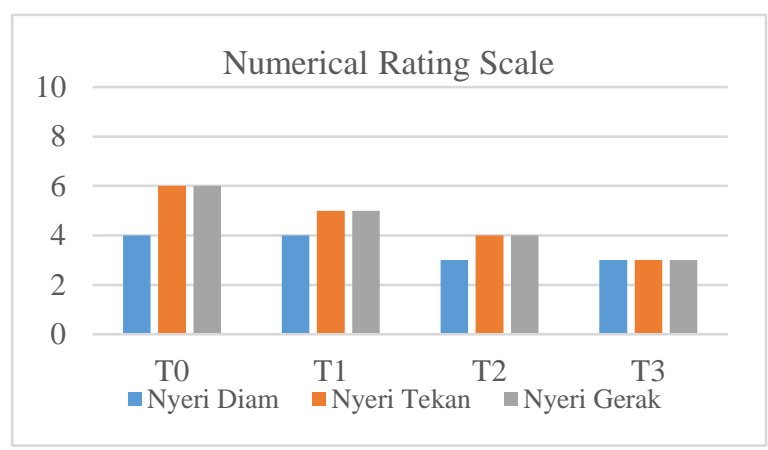

Penilaian nyeri pada area incisi di sternum dan tungkai kanan dilakukan menggunakan NRS mendapatkan hasil, yaitu:

a. Nyeri diam pada T0 dan T1 dengan nilai 4 yaitu nyeri berat, menurun pada $\mathrm{T} 2$ dan $\mathrm{T} 3$ menjadi 3 yaitu nyeri ringan

b. Nyeri tekan pada T0 dengan nilai 6 yaitu nyeri berat, menurun pada $\mathrm{T} 1$ menjadi 5 yaitu nyeri berat, selanjutnya menurun pada T2 menjadi 4 yaitu nyeri berat dan terakhir menurun pada T3 menjadi 3 yaitu nyeri ringan

c. Nyeri gerak dari T0 dengan nilai 6 yaitu nyeri berat, menurun pada $\mathrm{T} 1$ menjadi 5 yaitu nyeri berat, selanjutnya menurun pada T2 menjadi 4 yaitu nyeri berat dan terakhir menurun pada T3 menjadi 3 yaitu nyeri ringan.

\section{Evaluasi Derajat Sesak Napas dengan Borg} Scale

Gambar 2. Hasil Evaluasi Derajat Sesak Nafas

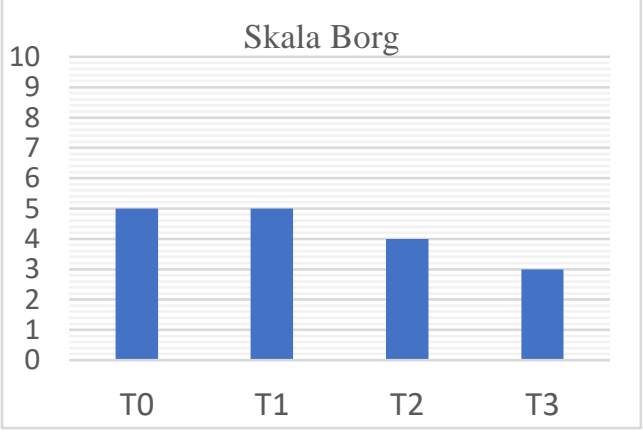

Pemeriksaan derajat sesak berdasarkan skala borg belum terdapat penurunan derajat sesak dari T0 ke T1 dengan nilai 5 yaitu sesak berat, kemudian turun pada T2 dengan nilai 4 yaitu agak berat dan turun lagi pada T3 dengan nilai 3 yaitu sedang.

\section{Evaluasi Ekspansi Thorak Dengan Pita Ukur}

Tabel 1. Hasil evaluasi ekspansi thoraks

\begin{tabular}{ccccc}
\hline Keterangan Hari & Axis & Inspirasi & Ekspirasi & Selisih \\
\hline T0 & Axilla & $97 \mathrm{~cm}$ & $96 \mathrm{~cm}$ & $1 \mathrm{~cm}$ \\
& ICS 4-5 & $99 \mathrm{~cm}$ & $98 \mathrm{~cm}$ & $1 \mathrm{~cm}$ \\
& Proc xypoideus & $92 \mathrm{~cm}$ & $90 \mathrm{~cm}$ & $2 \mathrm{~cm}$ \\
\hline T1 & Axilla & $97 \mathrm{~cm}$ & $96 \mathrm{~cm}$ & $1 \mathrm{~cm}$ \\
& ICS 4-5 & $99 \mathrm{~cm}$ & $98 \mathrm{~cm}$ & $1 \mathrm{~cm}$ \\
& Proc xypoideus & $92 \mathrm{~cm}$ & $90 \mathrm{~cm}$ & $2 \mathrm{~cm}$ \\
\hline T2 & Axilla & $98 \mathrm{~cm}$ & $97 \mathrm{~cm}$ & $1 \mathrm{~cm}$ \\
& ICS 4-5 & $100 \mathrm{~cm}$ & $99 \mathrm{~cm}$ & $1 \mathrm{~cm}$ \\
& Proc xypoideus & $93 \mathrm{~cm}$ & $91,5 \mathrm{~cm}$ & $1,5 \mathrm{~cm}$ \\
\hline T3 & Axilla & $100 \mathrm{~cm}$ & $98 \mathrm{~cm}$ & $2 \mathrm{~cm}$ \\
& ICS 4-5 & $102 \mathrm{~cm}$ & $100 \mathrm{~cm}$ & $2 \mathrm{~cm}$ \\
& Proc xypoideus & $94 \mathrm{~cm}$ & $92 \mathrm{~cm}$ & $2 \mathrm{~cm}$ \\
\hline
\end{tabular}


Pramudiana N. \& Pristianto A.

Fisiomu.2022 Vol 3(1): 8-15

DOI: $10.23917 /$ fisiomu.v3i1.12960

Pemeriksaan ekspansi thoraks menunjukkan adanya peningkatan selisih pada titik Axilla dari T0: $1 \mathrm{~cm}$ menjadi $2 \mathrm{~cm}$ pada T3 dan ICS 4-5 dari T0 :1 cm menjadi $2 \mathrm{~cm}$ pada T3 namun, belum ada peningkatan selisih pada titik Processus Xypoideus tetap $2 \mathrm{~cm}$ pada T0 dan T3.

\section{Pengukuran Aktifitas dan kemampuan Fungsional dengan Barthel Index}

Tabel 2. Hasil evaluasi kemampuan aktivitas dan fungsional menggunakan barthel index

\begin{tabular}{|c|c|c|c|c|c|c|}
\hline No. & Item yang dinilai & Skor & T0 & T1 & $\mathbf{T 2}$ & T3 \\
\hline 1. & Makan (Feeding) & $\begin{array}{l}\text { 0: Tidak mampu } \\
\text { 1: Butuh bantuan seperti memotong, mengoles } \\
\text { mentega, dll. } \\
\text { 2: Mandiri }\end{array}$ & 1 & 1 & 2 & 2 \\
\hline 2. & Mandi (Bathing) & $\begin{array}{l}\text { 0: Tergantung bantuan orang lain } \\
\text { 1: Mandiri }\end{array}$ & 0 & 0 & 0 & 0 \\
\hline 3. & $\begin{array}{l}\text { Perawatan } \quad \text { Diri } \\
(\text { Grooming) }\end{array}$ & $\begin{array}{l}\text { i } 0 \text { : Membutuhkan bantuan orang lain } \\
\text { 1: Mandiri dalam perawatan muka, rambut, } \\
\text { gigi dan bercukur }\end{array}$ & 0 & 0 & 0 & 1 \\
\hline 4. & $\begin{array}{l}\text { Berpakaian } \\
\text { (Dressing) }\end{array}$ & $\begin{array}{l}\text { 0: Tergantung bantuan orang lain } \\
\text { Sebagian dibantu (misal mengancing baju) } \\
\text { 1: Mandiri }\end{array}$ & 0 & 0 & 0 & 1 \\
\hline 5. & $\begin{array}{l}\text { Buang Air Kecil } \\
\text { (Bowel) }\end{array}$ & $\begin{array}{l}\text { 1 0: Inkontinensia atau pake kateter dan tidal } \\
\text { terkontrol } \\
\text { 1: Kadang inkontinensia (maks } 1 \times 24 \text { jam) } \\
\text { 2: Kontinensia (teratur untuk lebih dari } 7 \text { hari) }\end{array}$ & 0 & 0 & 0 & 0 \\
\hline 6. & $\begin{array}{l}\text { Buang Air Besar } \\
\text { (Blader) }\end{array}$ & $\begin{array}{l}\text { 0: Inkontinensia (tidak teratur atau perlu enema } \\
\text { 1: Kadang inkontinensia (sekali seminggu) } \\
\text { 2: Kontinensia teratur }\end{array}$ & 0 & 0 & 0 & 0 \\
\hline 7. & Penggunaan toilet & $\begin{array}{l}\text { 0: Tergantung bantuan orang lain } \\
\text { 1: Membutuhkan bantuan, tapi dapat } \\
\text { melakukan beberapa hal sendiri } \\
\text { 2: Mandiri }\end{array}$ & 0 & 0 & 0 & 0 \\
\hline 8. & Transfer & $\begin{array}{l}\text { 0: Tidak mampu } \\
\text { 1: Butuh bantuan untuk bisa duduk ( } 2 \text { orang) } \\
\text { 2: Bantuan kecil (1 orang) } \\
\text { 3: Mandiri }\end{array}$ & 0 & 1 & 1 & 1 \\
\hline 9. & Mobilitas & $\begin{array}{l}\text { 0: Immobile (Tidak mampu) } \\
\text { 1: Menggunakan kursi roda } \\
\text { 2: Berjalan dengan bantuan satu orang } \\
\text { 3: Mandiri (meskipun menggunakan alat bantu } \\
\text { sepertitongkat) }\end{array}$ & 0 & 0 & 0 & 0 \\
\hline 10. & Naik turun tangga & $\begin{array}{l}\text { 0: Tidak mampu } \\
\text { 1: Membutuhkan bantuan (alat bantu) } \\
\text { 2: Mandiri }\end{array}$ & 0 & 0 & 0 & 0 \\
\hline TOTAI & & & 1 & 2 & 3 & 5 \\
\hline
\end{tabular}

Berdasarkan tabel diatas, pada T0 nilai ketergantungan pasien adalah 1 artinya ketergantungan total kemudian berubah menjadi 5 pada T3 artinya tingkat ketergantungan berat. Pada 
T0 seluruh aktivitas fungsional masih bergantung pada bantuan orang disekitarnya, kemudian terjadi peningkatan pada aktivitas makan dari T1 nilai 1 berubah pada T2 dengan nilai 2 , kemudian perawatan diri dan berpakaian T0 nilai 0 berubah pada T3 dengan nilai 1 , serta pada aktivitas transfer pada T0 nilai 0 berubah menjadi 1 pada T1.

\section{PEMBAHASAN}

Pasien atas nama Tn. T usia 50 tahun berjenis kelamin laki-laki dengan diagnosa medis Pasca CABG et causa CAD3-VD telah diberikan penatalaksanaan fisioterapi sebanyak 3 kali terapi dengan modalitas Chest physiotherapy (deep breathing exercise,chest wall percussion, latihan batuk efektif dan positioning) dan latihan aktifpasif ekstremitas untuk mengatasi problematika fisioterapi seperti nyeri pada area sternum dan tungkai kanan bawah, penumpukan sputum, sesak nafas, penurunan ekspansi thoraks, penurunan kemampuan aktivitas dan fungsional.

\section{Nyeri dengan latihan aktif dan pasif pada ekstremitas}

Pada pasien ini, terdapat nyeri pada area incisi di area sternum dan tungkai kanan bawah yang diakibatkan dari bekas operasi. Kemudian diberikan latihan aktif dan pasif selama 3 kali. Latihan yang dilakukan yaitu menggerakkan ekstremitas atas dan bawah sambl mengambil nafas disetiap gerakannya dengan arah gerakan ke semua sisi sesuai kemampuan pasien. Hasil yang diperoleh berdasarkan skala nyeri menggunakan Numerical Rating Scale (NRS) saat T0 dan T1 untuk nyeri diam nilainya 4, kemudian turun pada T2 dan T3 menjadi 3. Untuk nyeri tekan dan nyeri gerak pada T0 awalnya 6 , berubah menjadi 5 pada T1, kemudian turun pada T2 menjadi 4 dan kembali turun pada T3 menjadi 3. Hal ini dipengaruhi dengan adanya bantuan dari obatobatan anti nyeri seperti injeksi paracetamol dan morfin yang jika dikombinasikan dapat menurunkan tingkat nyeri pasca operasi (Altun et al., 2017), kemudian dengan melakukan latihan aktif dan pasif pada ektremitas dapat mencegah terjadinya disfungsi sendi dan menjaga lingkup geraknya serta mencegah terjadinya permasalahan pada peredaran darah seperti deep vein trombosis (DVT) sehingga menjaga aliran darah dapat terdistribusi secara maksimal dan pada akhirnya dapat mengurangi nyeri yang dirasakan oleh pasien (Sultanpuram et al., 2016)

2. Sesak nafas dan penumpukan sputum dengan deep breathing exercise serta chest wall percussions

Pada pasien ini didapatkan hasil pemeriksaan sesak nafas menggunakan skala borg saat T0 adalah 5 (sesak nafas berat). Kemudian diberikan deep breathing exercise sebanyak 3 kali terapi. Hasil yang diperoleh saat T0 dan T1 belum terdapat perubahan, karena saat melakukan latihan kondisi pasien masih belum mampu untuk mengambil nafas dalam, sehingga udara tidak maksimal untuk masuk dan keluar serta kondisi pasien yang masih berada dalam efek sedatif dari anastesi. Pada T2 dan T3 terdapat penurunan sesak nafas menjadi 4 (sesak agak berat) dan 3 (sesak sedang). Penurunan derajat sesak nafas dipengaruhi oleh kondisi pasien yang mulai membaik, tingkat kesadaran yang baik dan juga keaktifan pasien dalam mengikuti edukasi dan latihan pernafasan dari fisioterapis sehingga mampu melakukan inspirasi dan ekspirasi sesuai toleransi pasien. Agar tidak terjadinya peningkatan kembali dari skala borg maka pasien diberikan edukasi mengenai pentingnya latihan pernafasan bagi kondisi pasca operasi Coronary Artery Bypass Grafting (CABG).

Manfaat dari deep breathing exercise dapat membantu pasien mendapatkan ekspansi penuh dari dinding thoraks selama pernafasan yang sangat penting untuk membantu 
Pramudiana N. \& Pristianto A.

Fisiomu.2022 Vol 3(1): 8-15

DOI: $10.23917 /$ fisiomu.v3i1.12960

memulihkan fungsi paru-paru, mengurangi atelektasis, meningkatkan volume paru, memfasilitasi pengeluaran sekresi dan meningkatkan pertukaran gas (Sultanpuram et al., 2016; Westerdahl, 2015). Kemudian, manfaat dari chest wall percussion yang dilakukan pada dinding thoraks bagian anterior dan posterior menggunakan tangan yang dibentuk seperti mangkok, sehingga memunculkan getaran yang akan ditransmisikan oleh dinding thoraks ke jaringan paru-paru yang terletak dibawahnya kemudian, cairan dapat teralirkan ke saluran udara yg lebih besar. Dilakukan sebanyak 25 kali dalam 10 detik selama 2 menit. Sehingga dapat membantu melepaskan sputum yang merupakan salah satu permasalahan pada pasien paska operasi CABG (Derakhtanjani et al., 2019).

\section{Ekspansi thorak dengan latihan aktif dan pasif pada ektremitas, latihan batuk efektif dan positioning}

Hasil pengukuran ekspansi thoraks setelah diberikan terapi sebanyak 3 kali, pada T0 dan T1 selisih inspirasi dan ekspirasi adalah $1 \mathrm{~cm}$ pada titik axilla serta ICS 4-5 namun pada titik processus xypoideus selisih inspirasi dan ekspirasi adalah $2 \mathrm{~cm}$. Hal ini disebabkan karena pada saat latihan kondisi pasien yang masih berada dalam pengaruh anastesi dan ketakutan pasien untuk berganti posisi sehingga menyebabkan perbedaan selisih dari pengukuran di masing-masing titik. Pada T2 selisih inspirasi dan ekspirasi adalah $1 \mathrm{~cm}$ pada titik axilla dan ICS 4-5, serta pada titik processus xypoideus selisihnya adalah $1,5 \mathrm{~cm}$, kemudian pada T3 selisih inspirasi dan ekspirasi berubah menjadi $2 \mathrm{~cm}$. Penurunan yang signifikan ini dikarenakan kondisi pasien yang mulai membaik, sehingga mampu mengikuti arahan dari fisioterapis, derajat sesak yang menurun, kemudian pasien mulai berani dan percaya diri untuk bergerak sehingga dapat meningkatkan kemampuan paru untuk melakukan inspirasi dan ekspirasi secara maksimal. Agar tidak terjadi menurunnya ekspansi thoraks maka pasien diberikan edukasi mengenai pentingnya latihan aktif dan pasif pada ekstremitas diiringi dengan latihan pernafasan.

Manfaat dari latihan aktif dan pasif pada ekstremitas adalah menjaga lingkup gerak sendi dan mencegah terjadinya disfungsi dari sendi dan peredaran darah, dapat membantu ekspansi thoraks agar lebih maksimal, kemudian manfaat dari latihan batuk efektif yaitu dapat meningkatkan pembersihan sekresi bronkus yang tertahan didalam paru-paru, sehingga mencegah atelektasis dan infeksi (Sultanpuram et al., 2016). Kemudian, positioning memberikan 2 manfaat utama yaitu meningkatkan ventilasi, perfusi, dan pertukaran gas serta membantu membersihkan kelebihan sekresi bronkus (Ahmad, 2018).

4. Kemampuan aktifitas dan fungsional dengan latihan aktif-pasif pada ekstremitas

Pasien dengan kondisi paska operasi CABG mengalami kesulitan untuk melakukan aktifitas dan fungsional secara mandiri seperti sediakala dikarenakan adanya sesak nafas, nyeri, ketakutan pasien untuk bergerak, efek sedatif dari anastesi dan pemasangan alat bantu pernafasan. Kemudian diberikan terapi latihan aktif dan pasif sebanyak 3 kali. Berdasarkan index barthel pada T0 yaitu 1 (ketergantungan total) yakni kemampuan makan yang membutuhkan bantuan dari orang disekitarnya, hal ini disebabkan kondisi pasien yang masih lemas dan belum sadar secara penuh.

Kemudian pada $\mathrm{T} 1$, terdapat perubahan nilai total menjadi 2 (ketergantungan total). Perubahan didapatkan adalah peningkatan kemampuan transfer pasien yang disebabkan kondisinya sudah mulai membaik dan tampak 
Pramudiana N. \& Pristianto A.

Fisiomu.2022 Vol 3(1): 8-15

DOI: $10.23917 /$ fisiomu.v3i1.12960

bersemangat sehingga untuk transfer membutuhkan bantuan orang lain. Selanjutnya pada T2 terjadi peningkatan kemampuan aktifitas dan fungsional menjadi 3 (ketergantungan total), hal ini dikarenakan peningkatan kemampuan untuk makan yang meningkat menjadi mandiri. Terakhir pada T3 didapatkan peningkatan dengan total nilai 5 (ketergantungan berat), dimana pasien sudah mampu untuk makan, perawatan diri, berpakaian secara mandiri. Namun untuk transfer masih membutuhkan bantuan dari sekitarnya. Hal ini dipengaruhi dengan menurunnya intensitas nyeri pada sternum dan ekstremitas bawah, penurunan sesak nafas, peningkatan ekspansi thoraks sehingga dapat meningkatkan kemampuan aktifitas dan fungsional pasien.

\section{KESIMPULAN}

Pada penelitian yang dilakukan kepada pasien dengan diagnosa medis pasca CABG et causa CAD3-VD dapat disimpulkan bahwa latihan aktif-pasif pada ekstremitas dapat membantu mengurangi nyeri pasca operasi, meningkatkan ekspansi thoraks serta meningkatkan kemampuan aktifitas dan fungsional. Deep breathing exercise dan chest wall percussions dapat mengurangi sesak nafas dan membantu proses mengeluarkan sputum. Latihan batuk efektif dan positioning dapat meningkatkan ekspansi thoraks.

\section{SARAN}

Saran yang diberikan penulis yaitu melakukan deep breathing exercise secara rutin dirumah, latihan aktif untuk ekstremitas, melakukan aktifitas sehari-hari sesuai batas kemampuan pasien, bila sesak, maka pasien disarankan untuk mengurangi aktifitas tersebut, serta untuk pihak keluarga adalah memberikan dukungan secara psikologis, sehingga harapannya pasien dapat bersemangat dalam menjalani hariharinya.

\section{DAFTAR PUSTAKA}

Ahmad, A. M. (2018). Essentials of Physiotherapy after Thoracic Surgery: What Physiotherapists Need to Know . A Narrative Review. The Korean Journal of Thoracic and Cardiovascular Surgery, 6516(51), 293-307. https://doi.org/10.5090/kjtcs.2018.51.5.293

Altun, D., Çınar, Ö., Özker, E., \& Türköz, A. (2017). The effect of tramadol plus paracetamol on consumption of morphine after coronary artery bypass grafting. Journal of Clinical Anesthesia, 36, 189-193. https://doi.org/10.1016/j.jclinane.2016.10.03 0

Arroyo-Rodríguez, C., Brito-Zurita, O. R., Sandoval-Navarrete, S., Solis-Vásquez, R., Ornelas-Aguirre, J. M., Olea-Hernández, C., ... Castelan-Ojeda, A. M. (2018). Risk factors for three-vessel coronary artery disease in patients of Northwest Mexico. Archivos de Cardiologia de Mexico, 88(5), 423-431.

https://doi.org/10.1016/j.acmx.2018.02.009

Derakhtanjani, A. S., Jaberi, A. A., Haydari, S., \& Bonabi, T. N. (2019). Comparison the effect of active cyclic breathing technique and routine chest physiotherapy on pain and respiratory parameters after coronary artery graft surgery: A randomized clinical trial. Anesthesiology and Pain Medicine, 9(5). https://doi.org/10.5812/aapm.94654

Kementrian Kesehatan Republik Indonesia. Indonesia; 2019 [update 26 september 2019 cited 07 desember 2020]. Available from: http://p2ptm.kemkes.go.id/kegiatanp2ptm/pusat-/hari-jantung-sedunia-hjs-

Purnomowati, A., Oehadian, A., \& Dewi, S. (2013). Karakteristik dan tatalaksana penderita penyakit jantung koroner dengan triple-vessel disease (3VD) di rumah sakit Dr. Hasan sadikin bandung periode tahun 2013. Departemen Ilmu Penyakit Dalam Fakultas Kedokteran Universitas Padjajaran, Vol. 13. 
Pramudiana N. \& Pristianto A. Fisiomu.2022 Vol 3(1): 8-15 DOI: $10.23917 /$ fisiomu.v3i1.12960

Seo, Y. G., Jang, M. J., Park, W. H., Hong, K. P., \& Sung, J. (2017). Inpatient cardiac rehabilitation programs' exercise therapy for patients undergoing cardiac surgery: National Korean Questionnaire Survey. Journal of Exercise Rehabilitation, 13(1), 76-83.

https://doi.org/10.12965/jer.1732806.403

Sultanpuram, S., Alaparthi, G. K., Krishnakumar, S. K., \& Ottayil, Z. C. P. (2016).
Physiotherapy Practice Patterns for Management of Patients Undergoing Thoracic Surgeries in India: A Survey. Surgery Research and Practice, 2016, 1-11. https://doi.org/10.1155/2016/9717489

Westerdahl, E. (2015). Optimal technique for deep breathing exercises after cardiac surgery. Journal of Italian Society of Anesthesiology, Analgesia, Resucitation and Intensive Care, 81(June 2014), 678-683. 
Pramudiana N. \& Pristianto A.

Fisiomu.2022 Vol 3(1): 8-15

DOI: 10.23917/fisiomu.v3i1.12960 